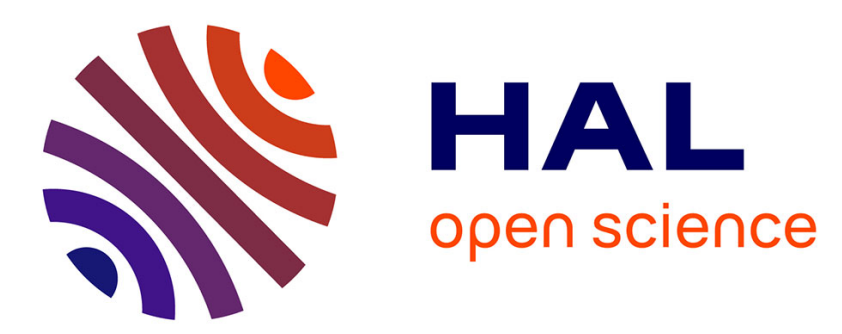

\title{
Bentazone adsorption and desorption on agricultural soils
}

\author{
Arnaud Boivin, Richard Cherrier, Michel Schiavon
}

\section{To cite this version:}

Arnaud Boivin, Richard Cherrier, Michel Schiavon. Bentazone adsorption and desorption on agricultural soils. Agronomy for Sustainable Development, 2005, 25 (2), pp.309-315. hal-00886288

\section{HAL Id: hal-00886288 \\ https://hal.science/hal-00886288}

Submitted on 1 Jan 2005

HAL is a multi-disciplinary open access archive for the deposit and dissemination of scientific research documents, whether they are published or not. The documents may come from teaching and research institutions in France or abroad, or from public or private research centers.
L'archive ouverte pluridisciplinaire HAL, est destinée au dépôt et à la diffusion de documents scientifiques de niveau recherche, publiés ou non, émanant des établissements d'enseignement et de recherche français ou étrangers, des laboratoires publics ou privés. 


\title{
Bentazone adsorption and desorption on agricultural soils
}

\author{
Arnaud BOIVIN ${ }^{\mathrm{a}, \mathrm{b} *}$, Richard CHERRIER**, Michel SCHIAVON*** \\ ${ }^{a}$ Present Address: George E. Brown Jr. Salinity Laboratory, USDA-ARS, 450 West Big Springs Road, Riverside, CA 92507-4617, USA \\ ${ }^{\mathrm{b}}$ Laboratoire Sols et Environnement, UMR 1120 INPL/ENSAIA-INRA, 2 avenue de la Forêt de Haye, BP 172, 54505 Vandœuvre-lès-Nancy Cedex, France
}

(Accepted 3 January 2005)

\begin{abstract}
Herbicide fate and transport in soils greatly depend upon adsorption-desorption processes. Batch adsorption and desorption experiments were performed with the herbicide bentazone using 13 contrasted agricultural soil samples. Bentazone was found to be weakly sorbed by the different soils, showing average Freundlich adsorption coefficients $\left(K_{f}\right)$ value of $1.4 \pm 2.3 \mathrm{mg}^{1-n_{f}} \mathrm{~L}^{n_{f}} \mathrm{~kg}^{-1}$. Soil organic matter content did not have a significant effect on bentazone sorption $\left(r^{2}=0.12\right)$, whereas natural soil $\mathrm{pH}$ appeared to be a key factor $\left(\mathrm{r}^{2}=0.68\right)$. A large part (average of $96.9 \pm 4.1 \%$ ) of the sorbed bentazone was released into aqueous solution after successive desorption steps, although some hysteresis was observed for each soil. Whereas soil $\mathrm{pH}$ was found to also influence bentazone desorption, other soil properties did not show well-defined relationships with sorption.
\end{abstract}

bentazone / adsorption / desorption / pH

\section{INTRODUCTION}

The abundant use of pesticides on cultivated fields is known to compromise soil and water quality. Several studies have shown their presence in both surface and groundwater (IFEN, 2004). Contamination of surface water and underlying water resources is a major concern since pesticides can pose immediate and/or long-term risks for ecosystems and humans (Garcia, 2003; Miersma et al., 2003; Wong et al., 2003).

Since pesticide behavior in soil strongly depends on adsorption-desorption phenomena, knowledge of these processes is important to accurately predict the mobility and fate of these chemicals in the subsurface (Bailey and White, 1970; Barriuso and Calvet, 1991; Coquet, 2003). Sorption influences pesticide degradation and leaching, and hence ultimately determines their fate in the environment (Laabs et al., 2000; Coquet, 2002; Wauchope et al., 2002; Coquet et al., 2004). While sorption of neutral compounds has been widely studied (Johnson and Sims, 1993; Gao et al., 1998a), sorption of weakly acidic chemicals such as bentazone (IUPAC name: 3-isopropyl-1H-2,1,3-benzothiadiazine-4(3H)-one 2,2-dioxide) has been far less investigated (Dubus et al., 2001).

Bentazone is a selective contact herbicide used for many crops. Its application to cultivated areas is a main concern since this pesticide is frequently detected in both surface and ground water (Lagana et al., 2002). Previous studies with bentazone have shown a very low mineralization rate, with the chemical being readily available for leaching immediately after application to three contrasted agricultural soils (Boivin et al., 2004). Bentazone and other ionized pesticides have anionic groups that cause sorption to be affected by $\mathrm{pH}$. This $\mathrm{pH}$ dependency of sorption is generally determined by artificially modifying the soil pH (Clausen et al., 2002).

Understanding pesticides desorption processes is also important since desorption determines the release rate and hence the potential mobility of pesticides in the subsurface (Huang et al., 1998; Gouy et al., 1999; Lesan and Bhandari, 2003). Several studies have shown the occurrence of hysteresis in the adsorptiondesorption process (van Genuchten et al., 1974; Kan et al., 1994; Huang and Weber Jr., 1997; Weber Jr. et al., 1998). This suggests that sorption of pesticides occurs with only a limited degree of reversibility depending upon both the chemical itself (e.g. its structure and solubility) and the soil properties involved (e.g. texture and soil physico-chemical parameters) (Gramatica and Di Guardo, 2002). Thus, soil can be regarded as an entity that is initially able to bind pesticides by functioning as a quasipermanent sink, but then also may release those products back into the soil solution (Gao et al., 1998b; Ding et al., 2002). The

\footnotetext{
* Corresponding author: aboivin@ussl.ars.usda.gov

** Richard.cherrier@ensaia.inpl-nancy.fr

*** Michel.schiavon@ensaia.inpl-nancy.fr
} 
Table I. Selected physico-chemical characteristics of bentazone.

\begin{tabular}{cccc} 
Molecular formula $\mathrm{M} . \mathrm{W} \cdot \mathrm{g} \cdot \mathrm{mol}^{-1}$ & $\mathrm{pKa}$ & $\begin{array}{c}\text { Solubility in water } \\
\mathrm{mg} \cdot \mathrm{L}^{-1} ; \mathrm{pH} \mathrm{7,22}{ }^{\circ} \mathrm{C}\end{array}$ \\
\hline Bentazone & & 3.3 & 570 \\
\hline
\end{tabular}

exact mechanisms of hysteretic adsorption/desorption of anionic pesticides remain largely unknown (Ding et al., 2002).

The aim of this work was to identify the main parameters affecting bentazone adsorption/desorption and to assess its potential mobility in the subsurface. To meet these objectives, thirteen contrasting agricultural soils (coarse, medium and finetextured soils) were selected and analyzed for their specific characteristics. Batch adsorption and desorption experiments were carried out and correlations between the standard Freundlich parameters $\left(\mathrm{K}_{\mathrm{f}}, \mathrm{n}_{\mathrm{f}}\right)$ and soil characteristics were established using descriptive statistical analyses.

\section{MATERIALS AND METHODS}

\subsection{Herbicides}

${ }^{14} \mathrm{C}$-ring-labelled bentazone was used in our experiments (radiochemical purity $>99 \%$; specific activity $6.69 \mathrm{MBq} \mathrm{mg}^{-1}$ ). Selected bentazone molecular characteristics are reported in Table I. Non-radio-labeled solutions were prepared separately with aqueous calcium chloride solution $(0.01 \mathrm{M})$ and then mixed with ${ }^{14} \mathrm{C}$-labelled methanol solutions to achieve the desired concentrations $\left(0.25 ; 1 ; 5\right.$ and $\left.10 \mathrm{mg} \mathrm{L}^{-1}\right)$. Methanol represented less than 0.01 percent of the total volume in the final solutions.

\subsection{Selected soils}

Samples were taken from the surface layers (0 to $15 \mathrm{~cm}$ ) of thirteen cultivated soils. The soils were selected on the basis of their texture, organic matter content and $\mathrm{pH}$ (Tab. II). Twelve soils were from the Lorraine area (France) and one soil from Brittany (Experimental station of Kerlavic, France). Soil types were classified into cambisols, calcisols and regosols according to the FAO classification (WRB, 1998). Soil samples were airdried, sieved to 2-mm, stored in the dark at room temperature $\left(20 \pm 2{ }^{\circ} \mathrm{C}\right)$ and sheltered from humidity.

\subsection{Sorption/desorption experiments}

Sorption isotherms were carried out using the standard batch equilibration method (OECD, 2000). In the first experiment, aqueous calcium chloride solutions $(0.01 \mathrm{M}, 10 \mathrm{~mL})$ were added to three replicates of $2 \mathrm{~g}$ of air-dried, sieved soil, in $25 \mathrm{~mL}$ Core ${ }^{\mathrm{TM}}$ glass centrifuge tubes, in order to bring the samples to water saturation. Tubes were shaken with a rotary agitator $(60 \mathrm{rpm})$ for $1 \mathrm{~h}$ at $20 \pm 2{ }^{\circ} \mathrm{C}$ in the dark and then centrifuged at $5000 \mathrm{~g}$ for 25 min using a Beckman, Avanti ${ }^{\mathrm{TM}} \mathrm{J}-25$ (Beckman Instruments, Inc, Fullerton, CA, USA). Next, supernatants were taken $(8 \mathrm{~mL})$, replaced by labeled solutions, after which the tubes were shaken again (same conditions as before). According to previous kinetic studies, equilibrium was assumed to be reached within the $16 \mathrm{~h}$ equilibration period (results not shown). Samples were next centrifuged similarly as before. The radioactivity of the supernatant solution was measured using a Packard 1900 tri-carb liquid scintillation analyzer (Packard Instrument Company, Meridien, CT, USA) after adding $10 \mathrm{~mL}$ of a scintillation cocktail (UltimaGold ${ }^{\mathrm{TM}}$, Packard Bioscience). The counting time was $10 \mathrm{~min}$ and a quench correction was made by the scintillator analyzer after calibration. Several tubes without soil were also shaken to serve as a control; they showed no loss of ${ }^{14} \mathrm{C}$. Thus, differences between the initial and equilibrium

Table II. Selected characteristics of the 13 cultivated soils. Soils are listed according to their organic matter content (from high to low).

\begin{tabular}{|c|c|c|c|c|c|c|c|}
\hline Soil type & Clay $(\%)$ & $\operatorname{Loam}_{(\%)}$ & Sand $_{(\%)}$ & O.M. $(\%)^{\mathrm{a}}$ & $\mathrm{pH}_{\mathrm{H}_{2} \mathrm{O}}$ & $\mathrm{C} / \mathrm{N}^{\mathrm{b}}$ & $\begin{array}{c}\text { C.E.C. }^{\mathrm{c}} \\
\left(\mathrm{cmol} \mathrm{kg}^{-1}\right)\end{array}$ \\
\hline Dystic Cambisol & 17.7 & 45.2 & 37.1 & 6.03 & 5.3 & 10.50 & 13.5 \\
\hline Stagnic Cambisol & 53.6 & 39.7 & 6.7 & 5.81 & 6.7 & 9.00 & 31.5 \\
\hline Calcaric Regosol $^{2}$ & 38.1 & 34.2 & 27.7 & 5.59 & 8.2 & 8.83 & 24 \\
\hline Fluvic Gleyic Cambisol & 51.6 & 42.9 & 5.5 & 4.80 & 6.2 & 8.66 & 25.4 \\
\hline Eutric Cambisol $^{2}$ & 10.4 & 19 & 70.6 & 3.66 & 6.2 & 10.47 & 7.9 \\
\hline Calcaric Regosol $^{1}$ & 33.4 & 25 & 41.6 & 3.63 & 7.9 & 8.66 & 14.7 \\
\hline Cambic Calsisol & 45.5 & 44.3 & 10.2 & 3.64 & 8.1 & 10.59 & 16.9 \\
\hline Vertic Stagnic Cambisol & 41.1 & 48.6 & 10.3 & 3.32 & 7 & 9.90 & 18.7 \\
\hline Cambic Stagnic Vertic Calcisol & 50.9 & 34.8 & 14.3 & 2.77 & 8 & 7.92 & 21.2 \\
\hline Stagnic Luvisol & 30.9 & 50 & 19.1 & 2.62 & 5.9 & 9.13 & 14.8 \\
\hline Fluvic Stagnic Cambisol & 11.4 & 22.5 & 66.1 & 1.50 & 5.8 & 9.60 & 5.5 \\
\hline Eutric Cambisol $^{1}$ & 12.7 & 13.8 & 73.5 & 1.43 & 6.4 & 10.13 & 4.6 \\
\hline Fluvic Cambisol & 20.1 & 55.4 & 24.5 & 1.08 & 5.5 & 9.29 & 9.6 \\
\hline
\end{tabular}

\footnotetext{
${ }^{\mathrm{a}}$ Organic matter content, ${ }^{\mathrm{b}}$ Organic carbon-nitrogen ratio, ${ }^{\mathrm{c}}$ Cation exchange capacity.
} 
concentrations were assumed to be due to sorption onto soil. Sorption isotherms were obtained by plotting the amount of chemical sorbed per unit weight of soil at equilibrium $\left(Q_{e}, m g\right.$ $\mathrm{kg}^{-1}$ ) versus the amount of chemical per volume of solution at equilibrium $\left(\mathrm{C}_{\mathrm{e}}, \mathrm{mg} \mathrm{L}^{-1}\right)$. The sorption data were described using the Freundlich equation:

$$
\ln \mathrm{Q}_{\mathrm{e}}=\ln \mathrm{K}_{\mathrm{f}} \times \mathrm{n}_{\mathrm{f}} \ln \mathrm{Ce}
$$

where $\mathrm{K}_{\mathrm{f}}$ and $\mathrm{n}_{\mathrm{f}}$ are the Freundlich parameters, characteristic for a particular herbicide-soil combination.

Desorption experiments were conducted immediately after the sorption experiments, starting at a concentration of $1 \mathrm{mg} \cdot \mathrm{L}^{-1}$, by successive dilution. First, supernatants were replaced with an aqueous calcium chloride solution $(0.01 \mathrm{M}, 8 \mathrm{~mL})$, after which the tubes were shaken at $20 \pm 2{ }^{\circ} \mathrm{C}$ for $16 \mathrm{~h}$. The suspensions were subsequently centrifuged and the radioactivity of the supernatant was measured (similarly as for the sorption experiments). The desorption process was repeated using the above procedure until the supernatant radioactivity became three times less than the liquid scintillation analyzer background noise (1.7 Bq).

Descriptive statistical analyses were carried out using the Statistica ${ }^{\circledR}$ software package version 6 (StatSoft France, Maison-Alfort, France). This included the construction of linear correlation models and a Principal Component Analysis.

\section{RESULTS AND DISCUSSION}

\subsection{Bentazone sorption parameters}

Freundlich parameters $\left(\mathrm{K}_{\mathrm{f}}\right.$ and $\left.\mathrm{n}_{\mathrm{f}}\right)$ and the corresponding sorbed percentages calculated for bentazone are given in Table III. The $\mathrm{K}_{\mathrm{f}}$ parameter is an empirical constant of the Freundlich model expressing soil sorbent capacity (sorption isotherm slope) for a given range of pesticide concentrations. In our study,

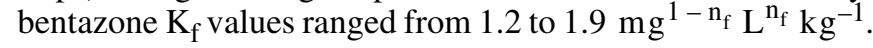
The highest $\mathrm{K}_{\mathrm{f}}$ value was observed for the dystic cambisol, a loamy-sandy soil with high organic matter content and low $\mathrm{pH}$, while the lowest $\mathrm{K}_{\mathrm{f}}$ values was found for the calcaric regosol ${ }^{1}$ $\left(\mathrm{Ca}^{2+}\right.$ saturated soil with $3.63 \%$ organic matter). We noticed that the distribution of $\mathrm{K}_{\mathrm{f}}$ values did not differ significantly from normal (Fig. 1). Also, the highest $\mathrm{K}_{\mathrm{f}}$ value (for the dystic cambisol) appears to be much different (an outlier) compared with those of the other soils. Thus, only a small amount of bentazone was gen-

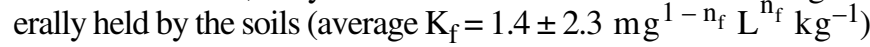
during the sorption experiments.

Bentazone is a polar chemical with a strong affinity for the liquid phase (von Gotz and Richter, 1999). Both characteristics can influence the sorption of bentazone. First, bentazone comprises a carboxylate group which may cause specific sorption reactions such as hydrogen bonding, while stable $\mathrm{Fe}^{3+}$ coordination bonding may be possible also (Clausen and Fabricius, 2001). This may cause some soils to exhibit a relatively strong sorption. On another hand, because of its high solubility, bentazone may be subject to relatively rapid diffusion in the soil matrix (Von Open et al., 1991).
Table III. Bentazone Freundlich constants $\left(\mathrm{K}_{\mathrm{f}}\right.$ in $\mathrm{mg}^{1-\mathrm{n}_{\mathrm{f}}} \mathrm{L}^{\mathrm{n}_{\mathrm{f}}} \mathrm{kg}^{-1}$ and $\mathrm{n}_{\mathrm{f}}$ ) and corresponding sorbed percentages (\% adsorbed). Percentages correspond to the average of the four sorbed percentages calculated for the four concentrations tested. Standard deviations of the sorbed percentages are also indicated.

\begin{tabular}{|c|c|c|c|}
\hline Soil type & $\mathrm{n}_{\mathrm{f}}$ & $\mathrm{K}_{\mathrm{f}}$ & $\%$ adsorbed \\
\hline Dystic Cambisol & 0.99 & 1.9 & $28 \pm 1$ \\
\hline Stagnic Cambisol & 1 & 1.4 & $22 \pm 1$ \\
\hline Calcaric Regosol $^{2}$ & 0.99 & 1.2 & $20 \pm 2$ \\
\hline Fluvic Gleyic Cambisol & 1 & 1.5 & $23 \pm 1$ \\
\hline Eutric Cambisol $^{2}$ & 1 & 1.3 & $21 \pm 1$ \\
\hline Calcaric Regosol $^{1}$ & 1 & 1.2 & $20 \pm 2$ \\
\hline Cambic Calsisol & 1 & 1.3 & $20 \pm 4$ \\
\hline Vertic Stagnic Cambisol & 1 & 1.2 & $20 \pm 1$ \\
\hline Cambic Stagnic Vertic Calcisol & 1 & 1.3 & $20 \pm 1$ \\
\hline Stagnic Luvisol & 1 & 1.4 & $22 \pm 1$ \\
\hline Fluvic Stagnic Cambisol & 1.01 & 1.4 & $22 \pm 1$ \\
\hline Eutric Cambisol $^{1}$ & 0.99 & 1.2 & $20 \pm 1$ \\
\hline Fluvic Cambisol & 0.99 & 1.5 & $23 \pm 2$ \\
\hline Average value & 1 & 1.4 & 22 \\
\hline Standard deviation & 0.01 & 0.2 & 2.3 \\
\hline
\end{tabular}

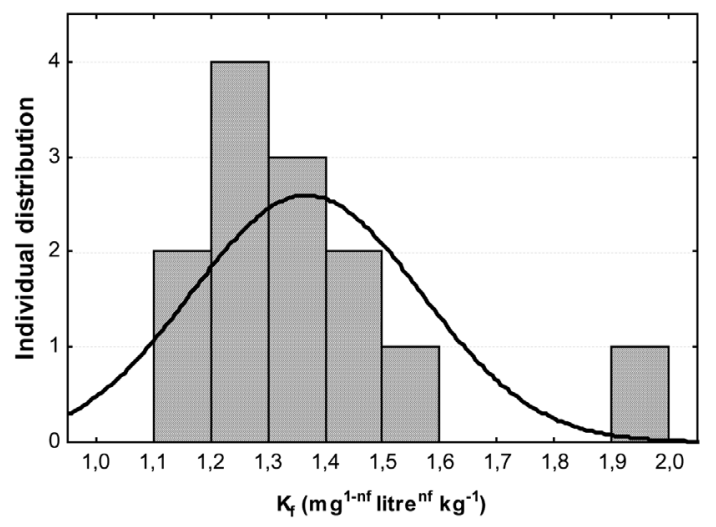

Figure 1. $\mathrm{K}_{\mathrm{f}}$ distribution (histogram) for bentazone assuming normal distribution.

Bentazone sorption isotherms were found to be linear $\left(\mathrm{n}_{\mathrm{f}}=1\right)$, with insignificant differences between the different soils; (Tab. III and Fig. 2). Thorstensen et al. (2001) previously obtained nonlinear sorption isotherms of bentazone for three Norwegian soils. Non-linearity was especially evident for a forest soil (gleyic podzol) with highly decomposed organic material (37.7\%) and a very low $\mathrm{pH}$ (2.9). In addition, the relatively high standard deviations could be due to the use of a commercially available triple formulation product. On the other hand, the sorption isotherm $n_{f}$ values of the other two soils in that same study (a dystric fluvisol and a stagnic pozoluvisol), representative of the most frequent soil types in cultivated areas of Norway, were close to those observed in our study $\left(\mathrm{n}_{\mathrm{f}} \approx 1\right)$; this even 


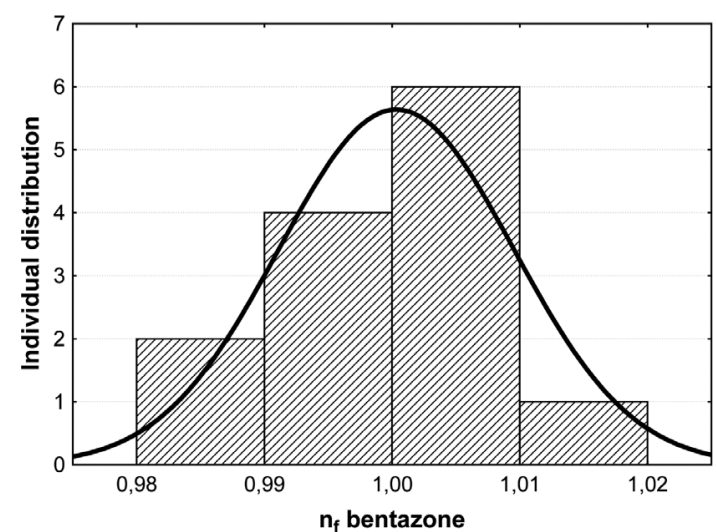

Figure 2. $\mathrm{n}_{\mathrm{f}}$ distribution (histogram) for bentazone assuming normal distribution.

though the Norway experiments involved much higher bentazone concentrations.

In our work, no explicative variable produced a significant improvement in the $\mathrm{n}_{\mathrm{f}}$ value predictions. Obviously, no significant differences existed between the $\mathrm{n}_{\mathrm{f}}$ values calculated for the 13 soils, and hence the $\mathrm{n}_{\mathrm{f}}$ value may be considered constant. Our results are consistent with those by Coquet $(2002 ; 2003)$ who also found it difficult to assess differences between $n_{f}$ values.

A preliminary descriptive statistical analysis was carried out for $\mathrm{K}_{\mathrm{f}}, \mathrm{n}_{\mathrm{f}}$, and several soil parameters (texture, organic matter content, $\mathrm{pH}, \mathrm{CEC}, \mathrm{Ca}, \mathrm{Fe}$ ) (results not shown). According to this preliminary analysis we decided to focus on soil organic matter content and $\mathrm{pH}$, since both presented clear correlations with bentazone sorption.

\subsection{Effect of soil organic matter content and $\mathrm{pH}$ on bentazone sorption}

Several previous studies of weakly acidic chemicals have indicated little or no effect of soil organic matter content on sorption (e.g. Barriuso and Calvet, 1991). This lack of correlation between sorption of anionic molecules and organic matter content has been attributed to repulsion caused by the negative charge of these compounds and the net negative charge of organic matter and clay minerals (Hamaker and Thompson, 1972). Our data do not suggest significant correlation between bentazone sorption and soil organic matter content (Fig. 3). This shows that bentazone has a relatively high affinity for the liquid phase irrespective of the soil organic matter content. For instance, the bentazone $K_{f}$ was estimated to be $1.4 \mathrm{mg}^{1-n_{\mathrm{f}}} \mathrm{L}^{\mathrm{n}_{\mathrm{f}}} \mathrm{kg}^{-1}$ for the

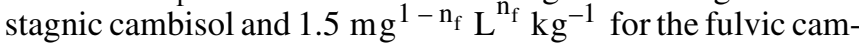
bisol having organic matter contents of $5.81 \%$ and $1.08 \%$, respectively (Tab. II). This is probably due to bentazone's physicochemical properties (i.e. solubility), and the nature of the interactions involved. The type of organic matter may also have an effect, but this aspect was not investigated as part of our study.

Several laboratory studies (e.g., Halfon et al., 1996; Carrizosa et al., 2000) have demonstrated an effect of soil $\mathrm{pH}$ on the sorption of weakly acidic compounds. The lower the $\mathrm{pH}$, the more

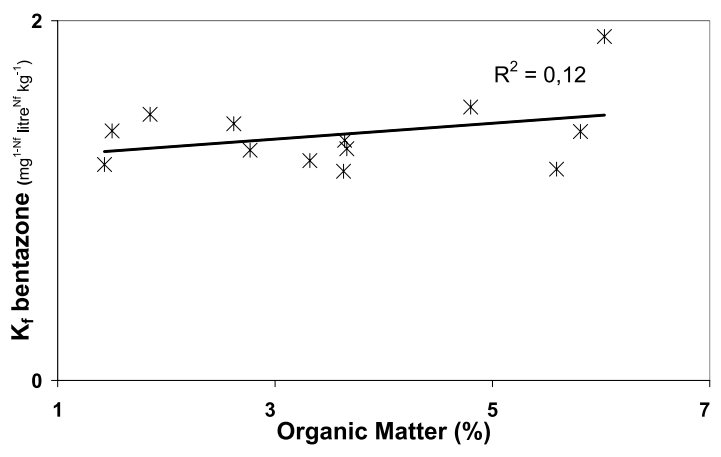

Figure 3. Bentazone $K_{f}$ in relation to the soil organic matter content of the 13 soils. The solid line represents the fitted curve; the coefficient of determination is also shown.

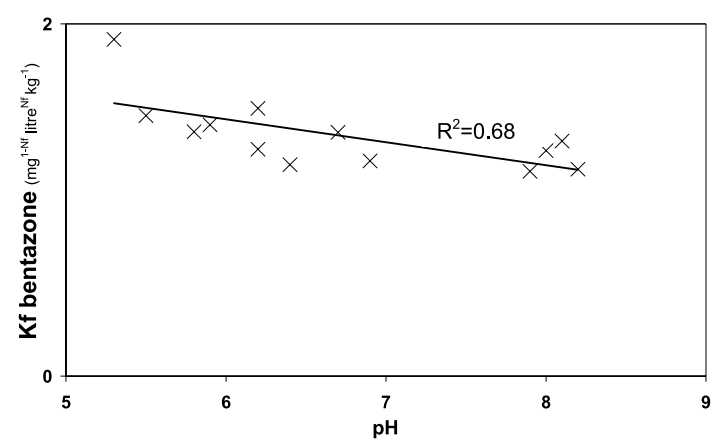

Figure 4. Bentazone $\mathrm{K}_{\mathrm{f}}$ in relation to $\mathrm{pH}_{\left(\mathrm{H}_{2} \mathrm{O}\right)}$ for the 13 soils. The solid line represents the fitted curve; the coefficient of determination is also shown.

sorption generally occurs. Such behavior has been observed mostly by artificially modifying the $\mathrm{pH}$, but very rarely by using contrasting soil samples (de Jonge and de Jonge, 1999; Carrizosa et al., 2001; Dubus et al., 2001). A descriptive statistical analysis would allow one to assess a possible link between soil $\mathrm{pH}$ and bentazone sorption since a significant correlation was observed in our study $\left(r^{2}=0.68 ; P \leq 0.05 ;\right.$ Fig. 4$)$. For the wide range of $\mathrm{pH}$ values investigated (5.30 to 8.20) some of the bentazone should be present in neutral form (1 to $3 \%$ ). Thus, bentazone sorption may be more sensitive to soil $\mathrm{pH}$ variations due to ionization. An ionization state is crucial when assessing the mechanisms of soil sorption, including nonspecific or specific sorption interactions (Calvet, 1989). Sorption of the neutral form likely involves non-specific interactions along with hydrophobic interactions and the presence of hydrogen bonds (Hamaker and Thompson, 1972). Sorption of the ionized form would be stronger than the neutral form due to repulsion between electro-negative charges of soil constituents and those of the ionized molecules.

Direct sorption involving the relatively few positive charges generally present in soils, may not be a significant mechanism for weakly acidic chemicals (Dubus et al., 2001). However, sorption could involve bivalent cations such as those between the ionized molecule and negatively charged surfaces of phyllosilicates or organic matter. In the case of bentazone, sorption 
Table IV. Multiple linear regression results for bentazone sorption. The model was established for 13 soils. Both O.M. (organic matter content) and $\mathrm{pH}$, significantly contributed to the regression $(P=$ 0.05). The multiple correlation coefficient between the observed $\left(\mathrm{K}_{\mathrm{f}}\right)$ and predicted $\mathrm{K}_{\mathrm{fp}}$ values indicated significant correlation (*).

\begin{tabular}{lc}
\hline Sorption multiple linear regression & $\begin{array}{c}\text { Multiple correlation } \\
\text { coefficient }\end{array}$ \\
\hline $\mathrm{K}_{\mathrm{fp}}$ bentazone $=0.060$ O.M. $-0.146 \mathrm{pH}+2.129$ & $0.82^{*}$ \\
\hline
\end{tabular}

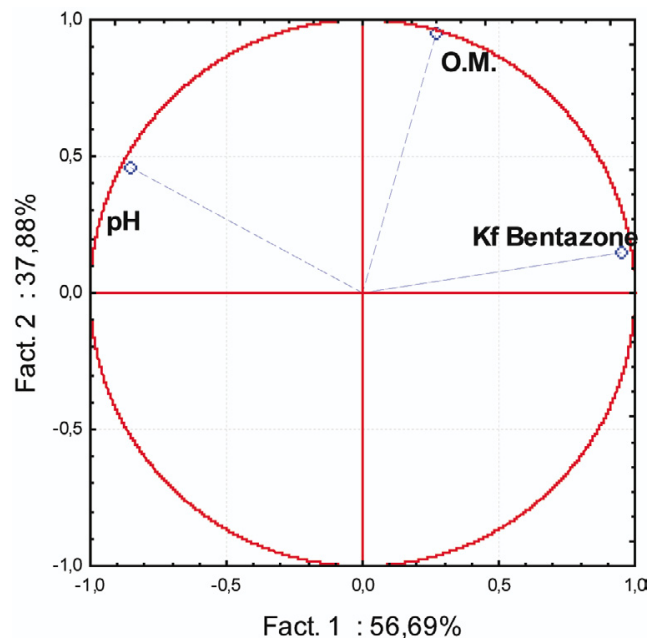

Figure 5. Principal component analysis representation (projection on 1, 2 planes) obtained for bentazone and selected soil characteristics from the 13 soils studied. $94.57 \%$ of the total variability could be explained by the two selected principal component axes.

of both neutral and ionized forms could explain the increased sorption at low $\mathrm{pH}$ values. Thus, the slight variation in bentazone sorption observed between the different soils $\left(\mathrm{K}_{\mathrm{f}}\right.$ ranging from 1.16 to 1.91 , corresponding to soil $\mathrm{pH}$ values of 8.2 and 5.3 respectively) may have been mainly caused by soil $\mathrm{pH}$.

\subsection{Descriptive statistical analyses for linear sorption}

The relationship between soil characteristics and bentazone sorption was studied by means of a Principal Component Analysis (Fig. 5). The analysis (plane 1,2) shows that bentazone sorption on cultivated soils is inversely related to $\mathrm{pH}$, while soil organic matter content has very little or no effect. In addition, multiple linear functions were derived in order to correlate the various soil characteristics with the $\mathrm{K}_{\mathrm{f}}$ values; (Tab. IV). Multiple linear regression combines relationships between the various soil parameters and the $\mathrm{K}_{\mathrm{f}}$ values, and leads to a linear predictive model for $\mathrm{K}_{\mathrm{f}}$ value (denoted by $\mathrm{K}_{\mathrm{fp}}$ here) (Golfinopoulos and Arhonditsis, 2002). The predicted $\mathrm{K}_{\mathrm{fp}}$ values in our study may be considered reliable since they were established using a wide array of soils that exhibited significant correlations (Tab. IV). The simple linear model may be useful for identifying areas (homogeneous soil types) where surface water resources could be threatened by pesticide contamination. The
Table V. Observed (data from R. Cherrier, unpublished) and predicted $\mathrm{K}_{\mathrm{fp}}$ values calculated for 3 soils (Brittany, France). The ratios $\mathrm{K}_{\mathrm{f}} / \mathrm{K}_{\mathrm{fp}}$ were calculated for each soil.

\begin{tabular}{lccc}
\hline Brittany soils & $\mathrm{K}_{\mathrm{f}}$ & $\mathrm{K}_{\mathrm{fp}}$ & $\mathrm{K}_{\mathrm{f}} / \mathrm{K}_{\mathrm{fp}}$ \\
\hline Kerlavic & 1.72 & 1.54 & 1.12 \\
Kerguéhennec & 1.6 & 1.22 & 1.31 \\
Champ Noël & 1.53 & 1.12 & 1.37 \\
\hline
\end{tabular}

predictive model would be useful also for identification of pesticides which are more easily leached through the soil profile.

The linear model was used to compare measured bentazone $\mathrm{K}_{\mathrm{f}}$ values obtained for three agricultural soils in Brittany, France (Cherrier R., unpublished data) with predicted values using the linear model for $\mathrm{K}_{\mathrm{fp}}$ (Tab. V). Although the values obtained with the experiments and the linear model were different, the ranking between the three soils was found to be the same for the experimental and predicted data. The ratios of $\mathrm{K}_{\mathrm{f}} /$ $\mathrm{K}_{\mathrm{fp}}$ were systematically higher than 1 (1.12 to 1.37 ), with only small differences between the data sets. This indicates that a simple correction factor should lead to $\mathrm{K}_{\mathrm{fp}}$ values that would closely approximate the measured data. This approach corroborates the fact that linear models constitute useful tools for predicting the adsorption of pesticide onto soil.

\subsection{Bentazone desorption}

Desorption controls the vulnerability of a pesticide to be degraded and/or leached at different times (Dur et al., 1998). In our study, desorption of bentazone exhibited hysteresis (results not further shown). Hysteresis is manifested by an increase in the difference between the adsorption and desorption isotherm slopes (Carrizosa et al., 2001; Worrall et al., 2001). Desorption behavior may reflect some of the interactions involved between the chemical and the various soils.

A large part of sorbed bentazone was released (average value of $96.9 \pm 4.1 \%$ ) after successive desorption steps, with no significant differences occurring between the 13 soils (Tab. VI.). Conceptually, the lack of similarity between adsorption and desorption observed due to the hysteresis is likely a result of binding to organic matter and mineral particles, particularly clay minerals (Neville et al., 2000). Though no significant correlation was observed between bentazone sorption, soil organic matter content, and clay content, some of the binding may have been strong enough to induce hysteresis and/or even irreversible sorption. During the sorption experiments, soil $\mathrm{pH}$ was shown to have a significant effect on bentazone sorption. Consequently soil $\mathrm{pH}$ may also influence the release of the pesticide. Multiple linear regressions carried out with the desorption data indicated some correlation between soil organic matter content, $\mathrm{pH}$ and the desorbed percentages of bentazone (Tab. VI). While for the wide range of soils studied, $\mathrm{pH}$ and soil organic matter contents did influence bentazone desorption, no significant multiple correlation coefficients could be obtained (Tab. VII).

We believe that pesticide diffusion may also play a role in the desorption process. Physical entrapment can lead to kinetic diffusion restrictions and could explain the slow release of bentazone 
Table VI. Bentazone desorbed percentages calculated for the 13 soils. Desorbed percentages pertain to the total amount of pesticides desorbed during the different desorption stages.

\begin{tabular}{|c|c|}
\hline Soil type & desorbed \% \\
\hline Dystic Cambisol & 99.8 \\
\hline Stagnic Cambisol & 98.8 \\
\hline Calcaric Regosol $^{2}$ & 91.5 \\
\hline Fluvic Gleyic Cambisol & 99.1 \\
\hline Eutric Cambisol ${ }^{2}$ & 99.3 \\
\hline Calcaric Regosol $^{1}$ & 86.2 \\
\hline Cambic Calsisol & 98.4 \\
\hline Vertic Stagnic Cambisol & 99.7 \\
\hline Cambic Stagnic Vertic Calcisol & 98.9 \\
\hline Stagnic Luvisol & 99.5 \\
\hline Fluvic Stagnic Cambisol & 93.4 \\
\hline Eutric Cambisol $^{1}$ & 99.1 \\
\hline Fluvic Cambisol & 95.9 \\
\hline Average value & 96.9 \\
\hline Standard deviation & 4.1 \\
\hline
\end{tabular}

Table VII. Multiple linear regression for bentazone desorption. The model was established for the 13 soils. Also shown is the multiple correlation coefficient between the observed $\left(\mathrm{K}_{\mathrm{f}}\right)$ and predicted $\left(\mathrm{K}_{\mathrm{fp}}\right)$ values.

\begin{tabular}{lc}
\hline Desorption multiple linear regression & $\begin{array}{c}\text { Multiple correlation } \\
\text { coefficient }\end{array}$ \\
\hline $\mathrm{P}_{\text {des. }}$ bentazone $=0.271$ O.M. $-1.946 \mathrm{pH}+108.96$ & 0.48 \\
\hline
\end{tabular}

during desorption (de Jonge and de Jonge, 1999). Bentazone has a high solubility $\left(570 \mathrm{mg} \mathrm{L}^{-1}\right)$, which allows it to diffuse relatively quickly into a large part of the soil matrix. Smaller concentration gradients during the desorption phase reduce the diffusion rates from relatively inaccessible sorption sites, even though they are still connected with the liquid phase, possibly contributing to apparent desorption hysteresis. In addition, if during the diffusion process pesticide molecules encountered new adsorption sites, water may not always be able to reach those sites during overall desorption.

Accurate interpretation of the bentazone desorption data is not easy because of the possible interplay of several processes. Desorption hysteresis appears to be the result of complex physicochemical processes between soils and the chemical involved, leading to multiple sorption processes. The data in this study do not permit a clear separation of the various processes responsible for hysteresis.

\section{CONCLUSIONS}

Our sorption experiments showed relatively little or no effect of soil organic matter content, while a lower $\mathrm{pH}$ statisti- cally enhanced bentazone sorption onto soil. The latter result was obtained without artificially modifying soil $\mathrm{pH}$ values. Simple linear models for predicting bentazone sorption such as those derived in this study may provide useful tools for optimal management of pesticides in field applications, and hence for preventing water contamination. Desorption appeared to be the result of a complex, time dependent interplay of several chemical and physical processes, leading to hysteresis. A more detailed conceptual explanation of the observed sorption and desorption processes requires additional information about the nature of the soil organic matter involved, including diffusion.

Acknowledgements: The authors wish to thank M. Th. van Genuchten at the USDA-ARS George E. Brown Jr. Salinity Laboratory, Riverside, CA, for his comments and his help in improving the manuscript.

\section{REFERENCES}

Bailey G.W., White J.L. (1970) Factors influencing the adsorption, desorption and movement of pesticides in soil, Residues Revue 1, 2992.

Barriuso E., Calvet R. (1991) Soil type and herbicides adsorption, Int. J. Environ. Anal. Chem. 46, 117-128.

Boivin A., Cherrier R., Perrin-Ganier C., Schiavon M. (2004) Time effect on bentazone sorption and degradation in soil, Pest Manage. Sci. 60, 809-814.

Calvet R. (1989) Adsorption of organic chemicals in soils, Environ. Health Persp. 83, 145-177.

Carrizosa M.J., Calderon M.J., Hermosin M.C., Cornejo J. (2000) Organosmectites as sorbent and carrier of the herbicide bentazone, Sci. Total Environ. 247, 285-293.

Carrizosa M.J., Koskinen W.C., Hermosin M.C., Cornejo J. (2001) Dicamba adsorption-desorption on organoclays, Appl. Clay Sci. $18,223-231$

Clausen L., Fabricius I. (2001) Atrazine, isoproturon, mecroprop, 2,4-D, and bentazone adsorption onto iron oxides, J. Environ. Qual. 30, 223-231.

Clausen L., Fabricius I., Madsen L. (2002) Adsorption of pesticides onto quartz, calcite, kaolinite and a-alumina, J. Environ. Qual. 30, 846857.

Coquet Y. (2002) Variation of pesticides sorption isotherm in soil at the catchment scale, Pest Manage. Sci. 58, 69-78.

Coquet Y. (2003) Sorption of pesticide Atrazine, Isoproturon, and Metamitron in the Vadose Zone, Vadose Zone J. 2, 40-51.

Coquet Y., Ribière C., Vachier P. (2004) Pesticide adsorption in the vadose zone: a case study on Eocene and Quaternary materials in Northern France, Pest Manage. Sci. 60, 992-1000.

de Jonge H., de Jonge L.W. (1999) Influence of pH and solution composition on the sorption of glyphosate and prochloraz to a sandy loam soil, Chemosphere 39, 753-763.

Ding G., Novak J.M., Herbert S., Xing B. (2002) Long-term tillage effects on soil metolachlor sorption and desorption behavior, Chemosphere 48, 897-904.

Dubus I.G., Barriuso E., Calvet R. (2001) Sorption of weak organic acids in soils: clofencet, 2,4-D and salicylic acid, Chemosphere 45, 767774.

Dur J.-C., Gouy V., Calvet R., Belamie R., Chaplain V. (1998) Influence of adsorption-desorption phenomena on pesticide runoff measured under controlled conditions, C.R. Acad. Sci. - Series IIA - Earth Planet. Sci. 327, 405-411. 
Gao J.P., Maguhn J., Spitzauer P., Kettrup A. (1998a) Sorption of pesticides in the sediment of the Teufelsweiher pond (Southern Germany). I: Equilibrium assessments, effect of organic carbon content and PH, Water Res. 32, 1662-1672.

Gao J.P., Maguhn J., Spitzauer P., Kettrup A. (1998b) Sorption of pesticides in the sediment of the teufelsweiher pond (Southern Germany). II: competitive adsorption, desorption of aged residues and effect of dissolved organic carbon, Water Res. 32, 2089-2094.

Garcia A.M. (2003) Pesticides exposure and women's health, Am. J. Ind. Med. 44, 584-594.

Golfinopoulos S.K, Arhonditsis G.B. (2002) Multiple regression models: A methodology for evaluating trihalomethane concentrations in drinking water from raw water characteristics, Chemosphere 47 , 1007-1018.

Gouy V., Dur J.-C., Calvet R., Belamie R., Chaplain V. (1999) Influence of adsorption-desorption phenomena on pesticide run-off from soil using simulated rainfall, Pest. Sci. 55, 175-182.

Gramatica P., Di Guardo A. (2002) Screening of pesticides for environmental partitioning tendency, Chemosphere 47, 947-956.

Halfon E., Galassi S., Bruggemann R., Provini A. (1996) Selection of priority properties to assess environmental hazard of pesticides, Chemosphere 33, 1543-1562.

Hamaker J.W., Thompson J.M. (1972) Adsorption, Marcel Dekker, New York.

Huang W., Weber Jr. W.J. (1997) A distribued reactivity model for sorption by soils and sediments. 10. Relationships between desorption, hysteresis, and the chemical characteristics of organic domains, Environ. Sci. Technol. 31, 2562-2569.

Huang W., Yu H., Weber Jr. W.J. (1998) Hysteresis in the sorption and desorption of hydrophobic organic contaminants by soils and sediments: 1. A comparative analysis of experimental protocols, J. Contam. Hydrol. 31, 129-148.

Johnson R.M., Sims J.T. (1993) Influence of surface and subsoil proprieties on herbicide sorption by Atlantic coastal plain soils, Soil Sci. $155,339-348$.

Kan A.T., Tu G., Tomson M.B. (1994) Adsorption/desorption hysteresis in organic pollutant and soil/sediment interaction, Environ. Sci. Technol. 28, 859-867.

Laabs V., Amelung W., Pinto A., Altstaedt A., Zech W. (2000) Leaching and degradation of corn and soybean pesticides in an Oxisol of the Brazilian Cerrados, Chemosphere 41, 1441-1449.

Lagana A., Bacaloni A., De Leva I., Faberi A., Fago G., Marino A. (2002) Occurrence and determination of herbicides and their major transformation products in environmental waters, Anal. Chim. Acta 462, 187-198.
Lesan H.M., Bhandari A. (2003) Atrazine sorption on surface soils: timedependent phase distribution and apparent desorption hysteresis, Water Res. 37, 1644-1654.

Miersma N.A., Pepper C.B., Anderson T.A. (2003) Organochlorine pesticides in elementary school yards along the Texas-Mexico border, Environ. Pollut. 126, 65-71.

Neville C.J., Ibaraki M., Sudicky E.A. (2000) Solute transport with multiprocess nonequilibrium: a semi-analytical solution approach, J. Contam. Hydrol. 44, 141-159.

OECD (2000) OECD guidelines for the testing of chemicals. Adsorption/ desorption using a batch equilibrium method, OECD Test Guideline 106, OECD Publications, Paris.

Thorstensen C.W., Lode O., Eklo O.M., Christiansen A. (2001) Sorption of bentazone, dichlorprop, MCPA and propiconazole in reference soils from Norway, J. Environ. Qual. 30, 2046-2052.

van Genuchten M.T., Davidson J.M., Wierenga P.J. (1974) An evaluation of Kinetic and Equilibrium Equations for the Prediction of Pesticide Movement Through Porous Media, Soil Sci. Soc. Am. Proc. 38.

von Gotz N., Richter O. (1999) Simulation of herbicide degradation in different soils by use of pedo-transfer functions (PTF) and non-linear kinetics, Chemosphere 38, 1401-1407.

Von Open B., Kördel W., Klein W. (1991) Sorption of nonpolar and polar compounds to soils: Processes, measurements and experience with the applicability of the modified OECD-guideline 106, Chemosphere 22, 285-304.

Wauchope R.D., Yeh S., Linders J.B.H.J., Kloskowski R., Tanaka K., Rubin B., Arata K., Werner K., Zev G., Michael L., John B.U. (2002) Pesticide soil sorption parameters: theory, measurement, uses, limitations and reliability, Pest Manage. Sci. 58, 419-445.

Weber Jr. W.J., Huang W., Yu H. (1998) Hysteresis in the sorption and desorption of hydrophobic organic contaminants by soils and sediments: 2. Effects of soil organic matter heterogeneity, J. Contam. Hydrol. 31, 149-165.

Wong W.Y., Zielhuis G.A., Thomas C.M.G., Merkus H.M.W.M. Steegers-Theunissen R.P.M. (2003) New evidence of the influence of exogenous and endogenous factors on sperm count in man, Euro. J. Obstet. Gyn. Reprod. Biol. 110, 49-54.

Worrall F., Fernandez-Perez M., Johnson A.C., Flores-Cesperedes F., Gonzalez-Pradas E. (2001) Limitations on the role of incorporated organic matter in reducing pesticide leaching, J. Contam. Hydrol. $49,241-262$

WRB (1998) World Reference Base for Soil Resources, FAO, ISRIC and ISSS $^{\complement}$, Food and Agriculture Organization of the United Nations, Viale delle Terme di Caracalla, 00100 Rome, Italy. 